\title{
The Relationship between Negotiation Style and Motivation in Unpaid Negotiations: A Case Study in Brazil
}

\author{
Maurício Bertoldi Sanches Neves ${ }^{1}$, Lara Bartocci Liboni ${ }^{2}$, Denise Alessandra Defina ${ }^{2} \&$ Dante Pinheiro Martinelli $^{2}$ \\ ${ }^{1}$ Polytechnic School of Engineering, São Paulo, SP, Brazil \\ ${ }^{2}$ Business Department, School of Business and Economics, University of São Paulo, Ribeirão Preto, SP, Brazil \\ Correspondence: Lara Bartocci Liboni, Business Department, School of Business and Economics, University of São \\ Paulo, Av. dos Bandeirantes, 3900, Monte Alegre - Ribeirão Preto, SP, Brazil. Tel: 55-16-3602-3903. E-mail: \\ laraliboni@usp.br
}

Received: February 10, 2013

Accepted: March 13, 2013

Online Published: May 12, 2013

doi:10.5430/ijba.v4n3p30

URL: http://dx.doi.org/10.5430/ijba.v4n3p30

\begin{abstract}
The outcomes of negotiations depend upon various factors that should be related directly to the profiles of the negotiators, such as motivation. Therefore, it is important to analyze the style, skills and motivation of each individual negotiator. In unpaid negotiations, it is particularly important to identify factors that motivate the negotiator and understand how they can influence the negotiation. This study sought to discover the main motivating factors in unpaid negotiators with different profiles at a nonprofit organization. Our approach was qualitative, exploratory and descriptive. A case study was performed in conjunction with the AIESEC (International Association of Students in Economic and Social Sciences), the world's largest youth-run organization, which provides a platform for youth leadership development. In this study, a qualitative questionnaire was administered to AIESEC sales personnel to ascertain their perceptions of the factors that motivated them in negotiations on behalf of their organization. The results revealed a number of motivating factors that were common to negotiators of all profiles, as well as other factors that motivated negotiators with specific negotiation styles.
\end{abstract}

Keywords: negotiation, motivation, profiles of the negotiators, unpaid negotiation

\section{Introduction}

Over the last decade, research has focused on means to maximize and optimize performance and results in negotiations. Because negotiators are individuals with unique needs and interests, various factors influence the outcomes of negotiations.

Walker, Churchill and Ford (1977) identify four main sets of factors that predict successful negotiations: the aptitudes and skills of the negotiators, compensation and financial incentives, psychological influences and managerial and organizational factors.

It is recognized that psychological factors, which are non-monetary incentives, such as recognition for a job performed well and opportunities for personal growth, are important because they motivate negotiators (Walker, Churchill \& Ford, 1977). Therefore, the needs and aspirations of negotiators can affect their performance and the outcomes of negotiations (Walker, Churchill \& Ford, 1977).

The motivation of the negotiators is an important factor that influences their performance in negotiations (Walker, Churchill \& Ford, 1977). There is a significant direct relationship between motivation and negotiation because the unmeasured needs and aspirations of the negotiators can affect the outcome.

In general, each negotiator has an individual set of skills and a unique negotiation style. It is important to analyze these styles and skill sets to understand the motivations of individuals and the means to achieve successful outcomes in negotiations.

It is a challenge to understand fully the factors that motivate individuals who have different negotiating styles. Motivating factors are particularly complex in negotiations that do not involve compensation or financial incentives. Therefore, this study addresses the following question: how do the negotiation styles of unpaid negotiators in a nonprofit organization influence their motivation? 
The study seeks to discover the main motivations of negotiators with different profiles who undertake unpaid negotiations on behalf of the AIESEC (International Association of Students in Economic and Social Sciences), a nonprofit organization.

\section{Negotiation}

\subsection{Underlying Variables in Negotiations}

Negotiation has also been studied by scholars and practitioners across a broad spectrum of disciplines for theoretical analysis and real world application at various levels (GONZALEZ, 2012). Martinelli and Almeida (1997) state that the three basic variables of power, time and information are always present in each negotiation, regardless of its purpose or importance. These authors argue that at least two of these three variables must be present and, preferably, interconnected in order for a negotiation to be effective (Martinelli \& Almeida, 1997).

Cohen (1980) defines power as the ability to accomplish goals and to exert control over people, events, situations and oneself. Power allows an individual to alter the status quo and attain intended goals. Hodgson (1994) describes the balance of power between the negotiating parties as one of the most interesting aspects of a negotiation.

Cohen (1980) argues that power is based on perception and is essentially neutral, a means instead of an end. Building on this assumption, Cohen (1980) proposes that anyone can achieve any goal provided that they are aware of their options, test assumptions, take calculated risks, have reliable information and believe that they have power (Cohen, 1980). Lewicki, Saunders and Minton (2001) define three sources of power: 1) information and expertise, 2) control over resources and 3) position within an organization's hierarchy.

In addition to power, the variable of time underlies negotiations. Martinelli and Almeida (1997) argue that negotiators should carefully consider the effects of time on a negotiation. The time that remains before a deadline or the conclusion of a negotiation can pressure negotiators to make concessions.

Cohen (1980) asserts that the third variable, information, is the crux of a negotiation and can lead to a successful outcome because information affects the assessment of reality and decision-making. Puchol (2005) characterizes information as a fundamental part of a negotiation, although most negotiators often ignore it. Effective negotiators tend to invest more time and effort to ensure that they have better quality of information. Puchol (2005) also states that it is necessary for a negotiator to draw upon their prior experience negotiating with another party to achieve successful outcomes in subsequent negotiations with that party.

Martinelli and Almeida (1997) note that information is related closely to the power to recognize the needs of others, thereby leading to successful negotiations and possibly affecting the assessment of reality and subsequent decision-making.

\subsection{Negotiator Profiles and Styles}

The study of negotiation styles is important not only to understand this topic but also to facilitate the evaluation and improvement of performance in negotiations. Martinelli and Almeida (1998) state that recognizing one's own style and that of the other party empowers a negotiator to plan and manage the negotiation.

Puchol (2005) identifies two key negotiator profiles based on personal attitudes and motivation - the competitive and the cooperative profiles. A negotiator with a cooperative profile seeks to maintain a good relationship with the other party and is effective in value creation or distribution negotiations. In contrast, negotiators with competitive profiles focus primarily on pursuing and achieving their goals.

Puchol (2005) acknowledges these two contrasting profiles and proposes a third option, a profile of a negotiator who can maintain friendly relationships without losing sight of his goals and is motivated by success and efficacy.

Leveraging relationships is an important element when negotiating in Brazil. Nevertheless, Brazilians often employ distributive and contingency bargaining. While the buyer is in a superior position, both sides in a business deal own the responsibility to reach agreement. They expect long-term commitments from their business partners and will focus mostly on long-term benefits. The primary negotiation style is competitive and Brazilians can be very aggressive negotiators. While proposals should demonstrate the benefits to both negotiating parties, neither of them should take attempts to win competitive advantages negatively. It is crucial to remain non-confrontational and avoid direct conflict throughout the bargaining exchange. Ultimately, the culture promotes a win-win approach and people value long-term business relationships. You will earn your counterparts' respect by maintaining a positive, persistent attitude. Do not openly show aggression or frustration (LOTHAR; KATZ 2007). 
Jung, Marcondes, Bergamini and Gottschalk are among the authors who have developed definitions of styles of negotiating (Martinelli \& Almeida, 1997). It is possible to note that, regardless of the author, these various styles can be divided into four major groups on the basis of personality traits (Table 1).

Table 1. Four systems for the classification of negotiation styles

\begin{tabular}{|c|c|}
\hline \multirow{4}{*}{ Jungian Model } & 1. Restrictive \\
\hline & 2. Artful \\
\hline & 3. Confrontational \\
\hline & 4. Amicable \\
\hline \multirow{4}{*}{ Gottschalk Classification } & 1. Hard \\
\hline & 2. Warm \\
\hline & 3. Numerical \\
\hline & 4. Negotiator \\
\hline \multirow{4}{*}{ LIFO $®$ Method } & 1. Giving and supporting $(\mathrm{G} / \mathrm{S})$ \\
\hline & 2. Taking over and controlling $(\mathrm{T} / \mathrm{C})$ \\
\hline & 3. Conserving and holding $(\mathrm{C} / \mathrm{H})$ \\
\hline & 4. Adapting and dealing (A/D) \\
\hline \multirow{5}{*}{ Marcondes Classification } & 1. Affirmative \\
\hline & 2. Persuasive \\
\hline & 3. Connecting \\
\hline & 4. Attracting \\
\hline & 5. Tension reducing \\
\hline
\end{tabular}

By examining the theories of negotiation styles, it is possible to note the following characteristics for four groups of negotiation styles:

- Group 1: An individual with a group 1 negotiation style is characterized by creativity, innovation and enthusiasm for new projects of great size. He or she needs to recognize the skills and abilities of others, placing an emphasis on ideas. The members of this group are sincere, although they may compromise their credibility by not always fulfilling their commitments. These negotiators may have dynamic, convincing and persuasive characters but they may be unstable and impulsive. A group 1 negotiator always seeks agreement between the parties and promotes a win-win approach.

- Group 2: A negotiator in group 2 values human life, has the ability to work in a team and always tries to please other people. His decision-making process is relatively slow and his style focuses on building relationships. He avoids challenging the other party and seeks acceptance. By always seeking to please other people, he is often inconsistent. A group 2 negotiator is cooperative, but he is considered to be reactive and inefficient in many cases.

- Group 3: A member of group 3 makes quick decisions, often worries about cost and time and is objective and organized. He is results-oriented and needs personal fulfillment. A group 3 negotiator is consistent, but he has difficulty accepting and listening to others because he lacks humility. He is characterized as rational, demanding, critical, decisive and authoritative, he tends to oversimplify and he has trouble working in teams.

- Group 4: The members of group 4 are meticulous, inquisitive, and insecure and avoid confrontation. This style of negotiator has ample credibility because he consistently fulfills his commitments, but he may not communicate with clarity. Because he is slow, careful, organized, serious and a perfectionist, he becomes reactive and tends to remain silent when under pressure.

Regardless of his style, the motivation of a negotiator is a major influence on his performance during negotiations.

\subsection{Negotiation and Motivation}

There is an avalanche of literature on motivation and motivational theories. For this study it was necessary to link motivation to negotiation.

De Dreu (2004) completed a large project on the relationship between motivation and negotiation. This researcher begins by asserting that it is impossible for a negotiator to have no conscious or unconscious motivation, whether 
explicit or implied. De Dreu (2004) claims that although individuals have many different motivations, the members of an organization pursue and structure their work on the basis of three broad classes of motivations and their influence on the information process and negotiation strategy:

- Social Motivation: the need to achieve a distribution or sharing of results between the two parties in a negotiation;

- Epistemic Motivation: the need to develop a complete and accurate vision and understanding of the world;

- Impression Motivation: the need to develop and maintain a good personal relationship with the other party in a negotiation.

Motivation is the inner drive that channels human beings to seek and achieve their goals (Anyim, Chidi \& Badejo, 2012). Understanding these motivations should be the priority of managers, since it is evident that high levels of motivation are desirable from the point of view of leaders and managers within organizations and individual employees.

\section{Negotiations by the AIESEC}

The AIESEC is the largest student organization in the world, present in 109 countries and in over 1700 universities, and recognized by UNESCO (United Nations Educational, Scientific and Cultural Organization). The AIESEC develops the leadership capabilities of its members through internal leadership programs. This organization also engages students and graduates in international student exchange and internship programs with profit and nonprofit organizations, enabling them to become global citizens and develop the skills and abilities that will allow them transform the environment in which they live.

The main objective of the Corporate Relations team of AIESEC is to establish and manage all of the organization's external relationships with current and future partners. In addition to seeking knowledge partners, the team creates and expands opportunities for companies and nonprofit organizations to receive trainees from around the world, increasing their global and entrepreneurial vision, facilitating cultural diversity and imbuing the working environment with new cultures and habits.

The members of the sales team of AIESC work directly with student exchange and internship programs. These members are responsible for creating new student exchange opportunities in businesses and non-governmental organizations and supporting the Incoming Exchange flow of exchange students to Brazil.

The sales team is also responsible for developing strategic partnerships for education, sponsorship relationships and exchange agreements with organizations. The sales process is similar to that of any commercial sales program and includes three stages: pre-sales, sales and post-sales.

In this context, pre-sales includes exploring target markets, creating and studying market segments, establishing contacts in organizations, researching organizations and defining account managers. The sales stage consists of meeting with the representatives of a company and applying sales techniques, redefining the proposal and closing an agreement to define a vacant (available) position.

The post-sales stage involves monitoring specific vacancies (unfilled positions), delivering resumes of interested parties to organizations, paying close attention to trainees after their arrival and resolving potential issues that may arise.

The salespeople are monitored with KPIs (key performance indicators) that measure their success in terms of the number of contracts signed and monitor the sale and delivery of products (delivery time). Sales planning involves identifying new positions aligned with market segments, external positioning and, in particular, developing products related to exchange programs. It is a great challenge for sales managers and directors to find ways to motivate the AIESEC salespeople, who receive no financial compensation and whose only rewards are learning and self-development.

Because the salespeople do not receive financial compensation or incentives for self-development and performance improvement, AIESEC salespeople need other motivating factors to successfully complete their work.

Therefore, it is clearly important that the AIESEC identify the major factors that motivate and influence their salespeople, who have different negotiation styles. Sales managers who have a better understanding of their salespeople can obtain better results. The present article seeks to identify these key factors and thereby help 
managers of unpaid sales forces to better identify the individual and collective needs of their teams and achieve better results in negotiations.

\section{Empirical Method}

In this study, the following question is proposed:

What is the influence of negotiation style on the motivation of an unpaid salesperson in a nonprofit organization?

This study seeks to identify the main motivating factors for unpaid negotiators with different profiles in a nonprofit organization, i.e., the AIESEC.

The specific objectives of this study are

- To evaluate the perceptions of the members of the AIESEC salespeople about motivations and influential factors in negotiations;

- To define the motivating factors for unpaid negotiators in student organizations;

- To propose new tools related to different negotiator profiles for the managers of sales teams;

- To measure and analyze the results obtained in this study.

A qualitative, exploratory and descriptive approach was applied in this study. A case study was performed in conjunction with the AIESEC. A qualitative questionnaire was used to identify the perceptions of the AIESEC salespeople about motivations in the negotiation work of their organization. Although the AIESEC has offices in other countries, only the Brazilian offices were included in this analysis.

Several variables were considered in this research:

- The length of experience of the AIESEC salesperson in the area of Corporate Relations because work experience is needed in order for a salesperson to have a strong foundation on which to base his or her opinions for the survey.

- The role of a salesperson in the hierarchical structure of AIESEC Corporate Relations because a negotiator's position in the organizational structure can directly influence his or her expectations and be related to the styles described above.

- The local committee in which the member (salesperson) conducts his activities because there may be cultural differences between geographical regions that could affect the perception of work in the AIESEC and thus the motivating factors of this individual.

A total of 200 questionnaires were given to salespeople who work directly in negotiation and sales in the AIESEC. These individuals were based in different AIESEC offices in Brazil, which provided richer geographical and cultural parameters for comparing the motivating factors in unpaid negotiations.

\section{Results}

\subsection{Motivating and Demotivating Factors in Unpaid Negotiations}

A total of 23 questionnaires were completed by salespeople from 11 different cities in seven different states in the South, Southeast and Northeast regions of Brazil. The mean age of the respondents was 21 years. It is estimated that there are between 150 and 200 salespeople in the AIESEC who work directly or indirectly on negotiation or sales. Thus, the return was just over $10 \%$ of the possible total respondents.

The questionnaire was designed to identify the key styles of each negotiator and to evaluate the factors that most strongly motivate each profile group of negotiators. The four group classification proposed above was chosen to evaluate the different profiles and to divide them into four main negotiation style groups.

The results of the survey were displayed in four parts that were related to the following profiles: 1) motivation for volunteering in student organizations, 2) motivation for working in sales, 3) motivation related to manager supervision and 4) considerations regarding negotiator styles. By analyzing the respondents' completed questionnaires, it was possible to identify the following characteristics that were present in the profiles of all negotiators regardless of their motivations:

- Development

- Growth

- Ability to perform 
- Interpersonal skills

- Impact

- Networking

- Passion

- Learning

- Belief in the purpose of the organization

- Performing without financial compensation

Table 2. Factors that motivate unpaid negotiators at the AIESEC

\begin{tabular}{cc}
\hline \multicolumn{3}{c}{ Distribution of factors that motivate sales work } \\
\hline $\begin{array}{c}\text { Learning to Negotiate, Development of Effective } \\
\text { Communication, Leadership/Impact }\end{array}$ & $41 \%$ \\
\hline $\begin{array}{c}\text { Networking, Group Work, Personal Relationships, Close } \\
\text { Manager Supervision and Feedback }\end{array}$ & $28 \%$ \\
\hline \multicolumn{2}{c}{ Recognition, Personal Achievement, Personal } \\
Development
\end{tabular}

Participants had to choose the factors that motivated them to work in sales from the four options above (Table 2), and each respondent could select up to two options. According to Table 2, the option that motivates the most salespeople in a nonprofit organization is what they can learn about the process of negotiation, the development of effective negotiation skills and the leadership/impact that they could achieve through their performance. In addition, there were several differences among the motivations of negotiators on the basis of their negotiation style.

Table 3. Motivational factors for four different negotiation styles

\begin{tabular}{ll}
\hline \multicolumn{1}{c}{ Negotiator styles } & \multicolumn{1}{c}{ Motivating characteristics } \\
\hline $\begin{array}{l}\text { Group 1: Hard, Catalyst, Confrontational or Adapting } \\
\text { and Dealing Styles }\end{array}$ & $\begin{array}{l}\text { Learning to negotiate, developing effective } \\
\text { communication, leadership/impact and networking, } \\
\text { working in a group, personal relationships, close } \\
\text { manager supervision and feedback. }\end{array}$ \\
Recognition, personal achievement, personal \\
Group 2: Warm, Supportive, Amicable or Giving and \\
Supporting Styles & $\begin{array}{l}\text { personal relationships, close manager supervision and } \\
\text { feedback. }\end{array}$ \\
Group 3: Negotiator, Controller, Restrictive or Taking & $\begin{array}{l}\text { Learning to negotiate, development of effective } \\
\text { communication, leadership/impact and achieving } \\
\text { objectives/results, autonomy, strategic vision. }\end{array}$ \\
and Controlling Styles & $\begin{array}{l}\text { Recognition, personal achievement, personal } \\
\text { development and learning to negotiate, development } \\
\text { of effective communication, leadership/impact. }\end{array}$ \\
Group 4: Numbers, Analytic, Artful or Conserving & \\
and Holding Styles &
\end{tabular}

Several motivating factors differ according to negotiation style (Table 3). For example, the factor "personal relationships" is an important factor for styles 1 and 2, but not for styles 3 and 4, which are more results-oriented than styles 1 and 2.

The main factors that may demotivate negotiators at a nonprofit organization were also analyzed. Respondents could choose up to 3 factors from 10 alternatives in the questionnaire. Regardless of the negotiator style, possible failure in achieving goals or results appeared to be the main demotivating factor. Other important factors were the intensity of work, lack of confidence related to lack of experience and absence of recognition for their work. Each negotiator 
style group characterized in the four group classification has the following key demotivating factors in a nonprofit organization (Table 4):

Table 4. Demotivating factors for four different negotiation styles

\begin{tabular}{ll}
\hline \multicolumn{1}{c}{ Negotiator styles } & \multicolumn{1}{c}{ Demotivating characteristics } \\
\hline $\begin{array}{l}\text { Group 1: Hard, Catalyst, Confrontational or Adapting } \\
\text { and Dealing Styles }\end{array}$ & $\begin{array}{l}\text { Not achieving goals/outcomes, lack of training and } \\
\text { low number of meetings. }\end{array}$ \\
$\begin{array}{l}\text { Group 2: Warm, Supportive, Amicable or Supporting } \\
\text { and Giving Styles }\end{array}$ & $\begin{array}{l}\text { Intensity of work, not achieving goals / outcomes, lack } \\
\text { of confidence/experience to perform the work. }\end{array}$ \\
$\begin{array}{l}\text { Group 3: Negotiator, Controller, Restrictive or Taking } \\
\text { and Controlling Styles }\end{array}$ & $\begin{array}{l}\text { Lack of recognition, not achieving goals / outcomes } \\
\text { and leadership profile. }\end{array}$ \\
$\begin{array}{l}\text { Group 4: Numbers, Analytic, Artful or Conserving } \\
\text { and Holding Styles }\end{array}$ & $\begin{array}{l}\text { Lack of financial rewards, not achieving } \\
\text { goals/outcomes and low number of meetings. }\end{array}$
\end{tabular}

Although all styles had common factors, such as not achieving goals and outcomes, there were several common demotivating factors in each style. One of the factors that may demotivate the negotiator is the lack of tasks and workload, i.e., meetings.

In the present study, $87 \%$ of the respondents agreed or strongly agreed that defined goals assist in motivating the negotiator, as negotiators and salespeople need clear objectives to carry out their activities in a consistent manner. Furthermore, $91 \%$ of the respondents strongly agreed that there is a feeling of accomplishment when a goal is reached. Thus, a results and goals-oriented manager can increase the motivation of their sales team.

Training and knowledge were also addressed in the present study and can be motivating factors for negotiators regardless of their profiles. The study aimed to observe the perception of negotiators with respect to the consequences of further training for negotiation outcomes. Knowing that achieving results is one of the main motivating factors for any negotiation style, $74 \%$ of the respondents agreed or strongly agreed that having more training or tools to enhance negotiation skills can be an efficient way of motivating the negotiation team.

Other factors that were studied included career development and the opportunity to be promoted within the nonprofit organization. These factors were analyzed to characterize how much a negotiator is motivated by the possibility of growth within their organization. A portion of negotiators of all styles seek to develop their skills and learning within the organization, and being promoted is another step in acquiring this knowledge. This characteristic may be related to the young age of the salespeople, who are at the start of their careers. In fact, almost $83 \%$ of the respondents agreed or strongly agreed that better career opportunities and organizational growth motivate them to achieve results.

Relationships and networking were significant factors for motivation in nonprofit organization work. Of the respondents, $70 \%$ agreed or strongly agreed that relationships are motivating factors in negotiations. Only 2 participants did not agree with this statement, and they used predominantly group 3 negotiation styles, which place more emphasis on individual goals, results and the achievement of goals as primary motivating factors. Most respondents, however, valued relationships and networking, which suggests that it is important for managers and sales leaders to provide interactive environments and spaces for networking as a way to motivate these negotiators to achieve better results.

The majority of survey participants strongly disagreed or neither agreed nor disagreed with the statement that financial rewards and awards are motivating factors in this type of negotiation. Therefore, financial rewards and awards so not motivate these negotiators. This finding is an expected result because the organization is a nonprofit entity, and its contributors seek knowledge and professional development. Nonetheless, it can be inferred that financial rewards or awards may be motivating factors for negotiators of styles three and four, who showed a greater tendency than negotiators of styles one and two to consider rewards and awards to be important in negotiations. In this case, negotiators with different styles had different perceptions of financial benefits as motivational factors.

Several survey questions were asked regarding whether manager supervision influences or could influence negotiator motivation. Even for negotiators with more individualistic styles and who prioritize individual work, the close participation and collaboration of their manager and leader substantially influence and motivate them to seek better results in their negotiations. As seen in Figures 1 and 2, 100\% of the respondents believed that manager supervision influences their will and motivation to work and achieve a higher level of performance in negotiations. 
When asked to consider the level of performance they achieved in negotiations and what could be performed to increase it, all respondents indicated that improvements were needed from both the individual and managerial points of view. Several issues could be addressed more productively, such as

1) Increase the number of strategic contacts and relationships - Networking

2) More experience and better handling of unforeseen events - Improvisation

3) Improvements in training - Training

4)Being more proactive

5) More manager supervision and consistency in performance - Fewer fluctuations in performance

6) Reconciling profiles and different negotiation styles - better utilizing the strengths of other negotiator profiles

As mentioned previously, $100 \%$ of the respondents believe that manager supervision assists in motivation, mainly through establishing trust, feedback on performance and development of skills. When asked to go into more detail about how supervisors could influence a respondent's motivation, the following factors were noted:

1) Coaching,

2) Increasing the amount of feedback on performance,

3) Inspiring confidence in the negotiator,

4) Improving supervision in assisting with difficulties,

5) Offering more recognition,

6) Functioning as a leader and not just a boss, integrating strategies and individual goals,

7) Leading by example,

8) Providing support for personal problems

\subsection{Considerations Regarding Negotiator Styles}

It is important to mention the perceptions that negotiators with different styles have regarding the characterization of those styles. The following brief remarks concern the findings with respect to each point of the research according to the different negotiation styles:

a - Relationship with the other party

Regardless of profile and style, all respondents considered their relationship with the other party to be important. Reasons cited included the long-term relationship, understanding the needs of the other party, the formation of new partnerships, trust and the relationship being a basis for negotiation.

b - Good results of negotiations

The perception of what comprises a good negotiation result is different for each style:

Group 1: Both sides are satisfied, leaving the meeting with new projects and partnerships

Group 2: Goals are reached, all sides are satisfied

Group 3: Results and sales are achieved

Group 4: Buyer confidence

c - Bluffing or threatening

A considerable proportion of the respondents said that they did not consider bluffing or threatening to be a good strategy. Those who said they did employ this method said that such a strategy may be used depending on the situation, especially in unstable and irregular environments, but they did not consider it to be ethical. Finally, bluffing was a method that was accepted by respondents and that may be used in some contexts, but threatening was an option that was rejected totally by respondents.

d - Dealing with conflict

The majority of the interviewees responded that they regard emotional intelligence during a confrontation to be important, seek ways to achieve a win-win scenario, think and innovate to find new solutions, attempt to understand 
the other party and even backtrack if necessary. Style groups 2 and 4 seek to avoid confrontation because these styles are more strongly relationship oriented.

e - Imposition of will in the negotiations

Although all participants said they do not seek to impose their opinions and wishes in negotiations, participants with a style more oriented toward group 3 demonstrated that they assert their will at times, although they are aware of the importance of giving and listening to the other party.

\section{f - Management of emotions}

Despite initially responding that they managed their emotions well, all research participants (upon reflection) admitted that their actions are somewhat diverse and they often fail to manage their emotions well. However, all participants demonstrated knowledge of the importance of managing their emotions to minimize the chance of failure in negotiations. Participants in group 1 showed less confidence than respondents in other groups about managing their own emotions.

$\mathrm{g}$ - Detailing the proposal at the beginning of the meeting

Style groups 1 and 4 prefer to explain the proposal before the initial conversation in a negotiation. Members of style group 2 prefer to develop an initial bond, understand the other party and subsequently explain the proposal, while those in style group 3 prefer objectivity not do not try to explain the proposal in detail at any point in the negotiation.

$\mathrm{h}$ - Making concessions during negotiation

Styles groups 1 and 4 believe that it is important to make concessions during negotiations, but only after assessing the situation and the possibilities for compromise. Style group 2 believes that making concessions is essential, while style group 3 thinks it is immaterial because they believe that what matters is achieving the goal.

i - Power

Regarding the use of power, each style group of negotiators can be characterized by the more frequent use of different powers, as defined by Cohen (1980):

Group 1: Power to recognize needs

Group 2: Powers of persistence, persuasion and recognizing needs

Group 3: Powers of persistence and bargaining, attitude

Group 4: Powers of attitude and identification

\section{Conclusions and Considerations for Future Research}

This study presented variables that can motivate unpaid negotiators who have different styles in their negotiations for nonprofit organizations.

Analysis of the results revealed that some motivating factors are common to negotiators of all profiles. However, other factors specifically motivate each negotiation style group. The aspects that influence each negotiator style were observed, and AIESEC salespeople's perceptions of motivations and influential factors in negotiations were assessed.

The sample consisted of salespeople with dynamic entrepreneurial profiles from different regions of the country. These salespeople were primarily young students beginning their undergraduate degrees. A main characteristic of these young people appeared to be the need for supervision. This may be associated with possible uncertainty about decisions and goals due to their age and inexperience. This question remains unanswered.

The survey showed that, despite common motivational factors, there are factors specific to each negotiation style of unpaid negotiators working at AIESEC. Each style has its own peculiarities regarding motivation. It is important to highlight the following points:

- Group 1: This type of negotiator, outside of a few exceptions, does not seek financial rewards but values the development and growth of their skills;

- Group 2: Their work is underpinned by passion and belief in the purpose of their organization and the positive effect of their work on society and other people;

- Group 3: They want to perform, that is, perform an activity, and they are focused by opportunities to build, enable learning and grow; 
- Group 4: They seek to expand their networking to generate contacts for their network of relationships for the present and future.

The motivational factors of each style group may be summarized as follows:

- Negotiators belonging to group 1 seek higher learning and the development of communication skills, are motivated by close managerial supervision, have greater ability to work in groups and are always open to feedback.

- Negotiators belonging to style 2 seek recognition for their actions, and their motivations for negotiation work include achievement, personal development and the creation of a vast network of contacts. They are better equipped to work in groups.

- Negotiators in style group 3 are focused on the results of their negotiations. They are motivated by greater autonomy and value the strategic vision of the process.

- Members of style group 4 also require recognition for their personal contribution and always seek to learn and develop their skills.

It is important to emphasize that goals and objectives should be managed for each salesperson because all participants, regardless of their position in the sales team, said that working with clear and defined goals motivates them in their work. This tool is important for achieving better results in negotiations. Thus, with correct management of individual goals, it is possible to reduce the level of failure in negotiations and thereby decrease the demotivation of the team, as failure in the task was identified as the negotiators' biggest demotivating factor.

Investment in negotiator training should be a priority because most participants are aware that better negotiation techniques could improve their results and thus increase personal motivation. To achieve this goal, the manager must introduce internal and external negotiation training and seek ways to identify individual and collective weaknesses such that they can be corrected. The sales manager should also consider that focusing on the close supervision of his team members should be a priority in his management role. Close supervision was a factor that all participants agreed was motivational, while an inadequate leadership profile was identified as a demotivating factor, especially for group 3.

The issue of compensation, as mentioned before, is not relevant to this type of negotiator. Awards and bonuses for recognition were motivating factors only for groups 3 and 4 and slightly more evident in the case of the group 3 .

The manager should also consider creating an environment that facilitates networking and interactions with contacts and businesses because this networking was seen as motivational by many of the negotiators, regardless of their profile. This is especially true given that a major motivation for working in sales is the creation of contacts and corporate networking. It is a fact that different styles influence negotiations; however, certain actions that transcended all styles were identified. Several features are common to all styles and thus some general measures can be taken. Adjustments can be made according to the peculiarities of each style.

A new method is proposed to increase sales management in nonprofit organizations in general. It is suggested that managers map the predominant profiles and styles of their negotiators according to the literature review outlined in the present study and implement custom solutions for each type of negotiator according to their style.

Although this study has focused on a nonprofit organization, it is feasible to consider future studies in other nonprofit organizations to confirm the results of this research. It is also possible to conduct research on each negotiating style, seeking to probe the motivational aspects of each group and considering factors that are exogenous to work or negotiations, such as the age of respondents. This factor, among others, may influence negotiators' perceptions regarding motivation in unpaid sales work.

\section{References}

Anyim, C.F. Chidi, O.C., \& Badejo, A.E. (2012). Motivation and Employees' Performance in the Public and Private Sectors in Nigeria. International Journal of Business Administration, 3(1). http://dx.doi.org/10.5430/ijba.v3n1p31

Cohen, H. (1980). Você pode Negociar Qualquer Coisa. Rio De Janeiro: Record.

Cohen, S. (2002). Negotiating Skills for Managers. Madison: Mcgraw-Hill.

De Dreu, CKW. (2004). Motivation in Negotiation. In Gelfand, M.J. Brett, J.M. (Eds.), The Handbook of Culture and Negotiation. Stanford: Stanford Business Books. 
Gonzalez, Raquel. (2013). Community Organizing Practice and Negotiation: Shared Principles and Methods. PhD diss.

Hodgson, J. (1994). Thinking on your Feet in Negotiations. London: Pitman Publishing.

Lewicki, R.L. Saunders, D.M., \& Minton, J.W. (2002). Fundamentos da Negociação. Porto Alegre: Bookman.

Lothar, Katz. (2007). Negotiating International Business: The Negotiator's Reference Guide to 50 Countries Around the World. Booksurge Llc.

Martinelli, D.P. (2006). Negociação, administraçãoo e sistemas: três níveis a serem inter-relacionados. Revista de Administração RAUSP, 41(4).

Martinelli, D.P., \& Almeida, A.P. (1997). Negociação: Como Transformar Confronto em Cooperação. São Paulo: Atlas.

Martinelli, D.P., \& Almeida, A.P. (1998). Negociação e Solução de Conflitos: do Impasse ao Ganha-Ganha através do Melhor Estilo. São Paulo: Atlas.

Puchol, L. (2005). El Libro De La Negociación. Espanha: Días De Santos.

Walker Junior, O.C. Churchill, G.A., \& Ford, N.M. (1977). Motivation and Performance In Industrial Selling: Present Knowledge And Needed Research. Journal of Marketing Resource, 14(2), 156-168. http://dx.doi.org/10.2307/3150465 